\title{
In reply: response to Al-Kassimi and Alhamad
}

\author{
Sang-Do Lee
}

Published online: 24 April 2013

(C) Springer Science+Business Media New York 2013

I read with great pleasure the comments from Professor Feisal A. Al-Kassimi and Dr Esam H. Alhamad, and am willing to respond to them.

Although chronic obstructive pulmonary disease (COPD) has no specific symptoms and signs, COPD is a clinical diagnosis in that it requires the presence of symptoms and/or exposure to risk factors, with persistent airflow limitation [1]. It is now widely recognized that COPD is not a single disease but a syndrome, encompassing a heterogeneous group of conditions that share the defining characteristic of chronic airflow limitation [2]. A variety of terms have been used to describe specific subgroups or phenotypes of COPD, and there is still no consensus on the number and definition of different COPD phenotypes. We therefore classified potential COPD phenotypes on the basis of clinical, physiological, and radiological characteristics [3]. We then reviewed their association with clinically meaningful outcomes.

We used the term "overlap syndrome" to indicate a clinical phenotype which includes the group of patients with overlapping characteristics of asthma and COPD. The definition of overlap syndrome - the coexistence in patients of increased airflow variability with incompletely reversible airway obstruction-was adopted from a previous review article published in Thorax [4].

Professor Al-Kassimi stated that overlap syndrome is too heterogeneous to be accepted as a distinct COPD phenotype. However, the old ATS Venn diagram had already classified obstructive airway disease into 11 different syndromes, six of which were overlap syndromes [5]. Previous epidemiological studies showed that a substantial number of patients have combined clinical features of asthma and

S.-D. Lee $(\bowtie)$

Department of Pulmonary and Critical Care Medicine and Clinical Research Center for Chronic Obstructive Airway Diseases, Asan Medical Center, University of Ulsan College of Medicine, 88, Olympic-ro 43 Gil, Songpa-gu,

Seoul 138-736, Republic of Korea

e-mail: sdlee@amc.seoul.kr
COPD [6-8], and recent cohort studies showed that these patients might have different prognoses [9-11]. These study results led to the consensus document on the COPD-asthma overlap phenotype which was published by the Spanish COPD experts group, who accepted overlap syndrome as a distinct clinical phenotype that may have a different natural history and prognosis [12].

Professor Al-Kassimi also stated that, because of its arbitrary definition, overlap syndrome is a "nonsyndome", and he worried that it could adversely affect phenotyping of COPD. However, consensus diagnostic criteria have been proposed for identification of the overlap phenotype. Major criteria include a strongly positive bronchodilator test (increase in $\mathrm{FEV}_{1} \geq 15 \%$ and $\geq 400 \mathrm{~mL}$ ), eosinophilia in sputum, and a personal history of asthma. Minor criteria include high total IgE, a personal history of atopy, and a positive bronchodilator test on two or more occasions. The overlap phenotype is diagnosed when two major criteria or one major and two minor criteria are met [12]. Furthermore, recent Spanish guidelines (GesEPOC) proposed COPD-asthma overlap as one of four clinical phenotypes that could potentially be incorporated into treatment guidelines [13, 14].

According to the comments of professor Al-Kassimi, "irreversible asthma" and "eosinophilic COPD" can be used as COPD phenotypes. Several studies have shown that COPD patients with sputum eosinophilia respond better to oral or inhaled corticosteroids [15-17]; however, whether controlling eosinophilic inflammation can modify disease progression and possibly affect mortality is unknown. The Spanish COPD experts group considered the term "eosinophilic COPD" as an alternative to the overlap phenotype, but rejected it because the name itself would require diagnostic tests not available at all health-care centers. We agree with their opinion, and believe that "eosinophilic COPD" can be regarded as an intermediate phenotype (endotype) of COPD rather than a clinical phenotype [18]. Many intermediate phenotypes have been proposed for COPD. However the precise relationships between them, and the appropriate 
therapeutic intervention, are still unclear. Therefore, these intermediate phenotypes need experimental validation [19].

Although several guidelines exist, the nosology of chronic obstructive airway diseases, including COPD and asthma, is still unclear [20]. Furthermore, there is substantial variation and uncertainty regarding use of the term "phenotype" in COPD. Undoubtedly, our potential COPD phenotypes and specific targeted therapy for each phenotype should be validated in further studies. The two phenotypes suggested by professor Al-Kassimi, irreversible asthma and eosinophilic COPD, can be regarded as part of the range of overlap syndrome. If it were found that these two phenotypes have distinct clinically-relevant outcomes different from those of overlap syndrome, they would be accepted as separate phenotypes.

Conflict of Interest Sang-Do Lee declares that he has no conflict of interest.

\section{References}

1. Rabe KF, Hurd S, Anzueto A, et al. Global strategy for the diagnosis, management, and prevention of chronic obstructive pulmonary disease: GOLD executive summary. Am J Respir Crit Care Med. 2007;176(6):532-55.

2. Han MK, Agusti A, Calverley PM, et al. Chronic obstructive pulmonary disease phenotypes: the future of COPD. Am J Respir Crit Care Med. 2010;182:598-604.

3. Friedlander AL, Lynch D, Dyar LA, et al. Phenotypes of chronic obstructive pulmonary disease. COPD. 2007;4:355-84.

4. Gibson PJ, Simpson JL. The overlap syndrome of asthma and COPD: what are its features and how important is it? Thorax. 2009;64:728-35.

5. American Thoracic Society Statement. Standards for the diagnosis and care of patients with chronic obstructive pulmonary disease. Am J Respir Crit Care Med. 1995;152:S77-120.

6. Soriano JB, Davis KJ, Coleman B, et al. The proportional Venn diagram of obstructive lung disease: tow approximations from the United States and the United Kingdom. Chest. 2003;124:474-81.
7. Zeki AA, Schivo M, Chan A, et al. The asthma-COPD overlap syndrome: a common clinical problem in the elderly. J Allergy. 2011;2011:861926.

8. Kim TB, Oh YM, Chang YS, et al. The reality of an intermediate type between asthma and COPD in practice. Respir Care. 2012;57(8):1248-53.

9. Hardin M, Silverman EK, Barr RG, et al. The clinical features of the overlap between COPD and asthma. Respir Res. 2011;12:127.

10. Hospers JJ, Postma DS, Rijcken B, et al. Histamine airway hyperresponsiveness and mortality from chronic obstructive pulmonary disease: a cohort study. Lancet. 2000;356:1313-7.

11. Vestbo J, Edwards LD, Scanlon PD, et al. Changes in forced expiratory volume in 1 second over time in COPD. N Engl $\mathrm{J}$ Med. 2011;365:1184-92.

12. Soler-Cataluña JJ, Cosio B, Izquierdo JL, et al. Consensus document on the overlap phenotype COPD-asthma in COPD. Arch Bronconeumol. 2012;48(9):331-7.

13. Miravitlles M, Calle M, Soler-Cataluña JJ. Clinical phenotypes of COPD: identification, definition and implications for guidelines. Arch Bronchoneumol. 2012;48(3):86-98.

14. Miravitlles M, José Soler-Cataluña J, Calle M, Soriano JB. Treatment of COPD by clinical phenotypes. Putting old evidence into clinical practice. Eur Respir J. 2012. doi:10.1183/09031936. 00118912.

15. Brightling CE, Monteriro W, Ward R, et al. Sputum eosinophilia and short-term response to prednisolone in chronic obstructive pulmonary disease: a randomized controlled trial. Lancet. 2000;356:1480-5.

16. Brightling CE, McKenna S, Hargadon B, et al. Sputum eosinophilia and the short term response to inhaled mometasone in chronic obstructive pulmonary disease. Thorax. 2005;60:193-8.

17. Siva R, Green BH, Brightling CE, et al. Eosinophilic airway inflammation and exacerbations of COPD: a randomized controlled trial. Eur Respir J. 2007;29:906-13.

18. Loscalzo J, Kohane I, Barabasi AL. Human disease classification in the postgenome era: a complex system approach to human pathobiology. Mol Syst Biol. 2007;3:124.

19. Agusti A, Vestbo J. Current controversies and future perspectives in chronic obstructive pulmonary disease. Am J Respir Crit Care Med. 2011;184:507-13.

20. Snider GL. Nosology for our day: its application to chronic obstructive pulmonary disease. Am J Respir Crit Care Med. 2003;167:678-83. 